\title{
Severe bronchial asthma requiring ventilation. A review of 20 cases and advice on management
}

\author{
A. K. WEBB \\ M.B., M.R.C.P.
}

\author{
A. H. Bilton \\ M.B., B.S., F.F.A.R.C.S.
}

\author{
Gillian C. HaNSON \\ M.B., F.R.C.P. \\ Intensive Therapy Unit, Whipps Cross Hospital, Leytonstone, London E11 1NR
}

\begin{abstract}
Summary
The natural history and outcome of $\mathbf{2 0}$ asthmatics who required mechanical ventilation is reviewed. Seven of these patients died. The majority of the deaths could have been prevented if:

(1) The patient had been followed-up in an asthma clinic and had been fully informed of the danger of an asthmatic attack.

(2) The medical staff had been trained more fully in the evaluation and management of a severe asthma attack.

Careful sequential assessment will enable timely transfer of patients with severe bronchial asthma to a unit experienced in their management.
\end{abstract}

\section{Introduction}

Few patients in status asthmaticus come to intermittent positive pressure ventilation. The reasons appear to be twofold, either the patients respond to maximum conventional therapy of intravenous steroids and bronchodilators in hospital (Editorial, 1975), or else death can occur quite unexpectedly in hospital or home. Retrospective studies have attempted to implicate avoidable factors (Cochrane and Clark, 1975). The ventilation of asthmatics has been described in the past (Ambiavagar, Sherwood Jones and Roberts, 1967), however, details of individual patient management are few. The natural history and outcome of 20 asthmatics ventilated on the Intensive Therapy Unit at Whipps Cross Hospital between 1967 and 1977 are presented. Possible avoidable factors are considered.

\section{Patients and methods}

The case notes of all patients with a diagnosis of status asthmaticus admitted to the Intensive Therapy Unit between 1967 and 1977 were examined. Twenty patients who were ventilated and had a clinical history of reversible airways disease were included in the study. Patients with a history of bronchitis, according to the MRC definition, were excluded.

The following factors (where available in the notes) were noted for each individual patient:

(a) Patient characteristics to include age, sex, atopic status and present maintenance therapy regime.

(b) History of illness, treatment and assessment before ventilation.

(c) Factors which precipitated the decision to ventilate.

(d) Patient management during ventilation.

(e) Outcome of ventilation and patient follow-up.

\section{Results}

\section{Patient characteristics}

Twenty patients were included in the study, of whom 14 were male and 6 were female. Age range was 5-64 years. Fourteen patients had skin tests, of these 7 were atopic and 7 were non-atopic. Skin tests were not performed in the remaining 6 patients. Ten patients were currently receiving oral steroids (range $2.5 \mathrm{mg}$ daily to $15 \mathrm{mg}$ thrice daily). Thirteen patients had had previous hospital admissions for exacerbation of asthma.

Factors possibly precipitating the asthma attack, standard of clinical-assessment and treatment before ventilation (Table 1)

In 7 patients, the aetiology of the asthma attack was attributed to an intercurrent infection, characterized by influenza-like symptoms, or production of purulent sputum. Staphylococci were isolated from the sputum of one patient (no. 20), she later developed multiple lung abscesses whilst being ventilated. In the remaining 6 patients, no pathogenic organism was isolated.

In 10 patients the attack was related to intractable wheezing unresponsive to self-medication at home, 
TABLE 1. Factors possibly precipitating the asthma attack, standard of clinical assessment and treatment before ventilation

\begin{tabular}{|c|c|c|c|c|}
\hline & Patient & Possible precipitating factors & $\begin{array}{c}\text { Scored } \\
\text { assessment }\end{array}$ & $\begin{array}{c}\text { Treatment } 24 \mathrm{hr} \text { before ventilation of patients in hospital for } \\
\text { more than one day }\end{array}$ \\
\hline 1 & JA & Not known & 4 & $\begin{array}{l}\text { Hydrocortisone } 100 \mathrm{mg} \\
\text { Aminophylline } 1 \mathrm{~g}\end{array}$ \\
\hline 2 & GB & Acute wheezy attack & 2 & - \\
\hline 3 & EB & Infection & 7 & $\begin{array}{l}\text { Hydrocortisone } 200 \mathrm{mg} \text { 3-hourly } \\
\text { Aminophylline } 1 \mathrm{~g} 12 \text {-hourly }\end{array}$ \\
\hline 4 & EB & Infection & 2 & $\begin{array}{l}\text { Hydrocortisone } 200 \mathrm{mg} 3 \text {-hourly } \\
\text { Aminophylline } 1 \mathrm{~g} 12 \text {-hourly }\end{array}$ \\
\hline 5 & RC & Acute wheezy attack & 4 & Oral steroids $20 \mathrm{mg} 6 \mathrm{hr}$ before arrest \\
\hline 6 & BC & Wheezing during pregnancy & - & - \\
\hline 7 & $\mathrm{KC}$ & Infection & 4 & Antibiotics \\
\hline 8 & FB & Infection & 5 & $\begin{array}{l}\text { Hydrocortisone } 300 \mathrm{mg} \text { 6-hourly } \\
\text { Aminophylline } 500 \mathrm{mg} \text { 6-hourly }\end{array}$ \\
\hline 9 & PD & Wheezing attack & 2 & $\begin{array}{l}\text { Hydrocortisone } 100 \mathrm{mg} \text { 6-hourly } \\
\text { Aminophylline } 500 \mathrm{mg} \text { 6-hourly }\end{array}$ \\
\hline 10 & GG & Wheezing attack & 4 & $\begin{array}{l}\text { Dexamethasone } 2 \mathrm{mg} \text { i.m. } \\
\text { Aminophylline stopped }\end{array}$ \\
\hline 11 & HН & Wheezing attack & 1 & Observed in day ward (too breathless to give history) \\
\hline 12 & AH & Infection & - & $\begin{array}{l}\text { Prednisolone } 60 \mathrm{mg} \text { orally } \\
\text { Aminophylline } 2 \mathrm{~g}\end{array}$ \\
\hline 13 & NH & Not known & - & ? \\
\hline 14 & JJ & Intractable wheezing & 5 & Prednisolone $80 \mathrm{mg}$ \\
\hline 15 & BK & Not known & - & - \\
\hline 16 & $\mathbf{L M}$ & Acute wheezing attack & - & - \\
\hline 17 & 10 & Wheezing attack & - & - \\
\hline 18 & $\mathbf{J P}$ & Infection & 4 & Methylprednisolone sodium succinate $2 \mathrm{mg}$ \\
\hline 19 & RS & Wheezing attack & 7 & $\begin{array}{l}\text { Hydrocortisone } 200 \mathrm{mg} \text { 4-hourly } \\
\text { Aminophylline } 500 \mathrm{mg} \text { 12-hourly }\end{array}$ \\
\hline 20 & BS & Infection & 5 & $\begin{array}{l}\text { Hydrocortisone } 500 \mathrm{mg} \text { 6-hourly } \\
\text { Aminophylline } 500 \mathrm{mg} \text { 6-hourly }\end{array}$ \\
\hline
\end{tabular}

consisting of a bronchodilator, and/or subcutaneous adrenaline. Two of the 10 patients had recently ceased taking their oral steroids, without prior consultation with their doctor. One patient (no. 6) noticed increasing wheezing during her pregnancy and went into acute status asthmaticus following the administration of thiopentone for induction of anaesthesia for the removal of retained products post partum. This patient (a nurse) had failed to inform the anaesthetist that she suffered from asthma; no bronchospasm was detected on pre-operative examination.

One patient (no. 17) developed acute bronchospasm and subsequent respiratory arrest following ingestion of a nut-containing chocolate. Patient no. 2 was found unconscious at home having used his inhaler at least 20 times that day to abort wheezing.

Thus, in 12 of the 20 patients there was a positive aetiological factor which in 5 of the patients could have been avoided. Judgement of the severity of each patient's asthma attack was made on the basis of scoring each factor in a standard assessment of asthma according to Stark (1972) (Table 2). A total of 8 points was possible.

Fourteen patients were seen before ventilation to whom it was possible to ascribe a score on the basis of information in the notes.
TABLE 2. Standard assessment of asthma (Stark, 1972)

\begin{tabular}{llc}
\hline & & Points \\
\hline History & Reference to exercise tolerance & 1 \\
Examination & Pulse rate and pulsus paradoxus & 2 \\
& Respiratory rate & 1 \\
Investigation & Peak expiratory flow rate or spirometry & 1 \\
& Arterial blood gas tensions & 1 \\
& Chest radiograph & 1 \\
& Electrocardiogram & 1 \\
& \multicolumn{2}{c}{ Total points possible } \\
\hline
\end{tabular}

TABLE 3. Number of patients assessed according to the factors (Table 2). Total number of patients studied 14

Assessment factor

Exercise tolerance

Pulse rate

Pulsus paradoxus

Respiratory rate

Peak expiratory flow rate or spirometry

Blood gases

Electrocardiogram

Chest radiograph 
Table 3 shows the number of patients who were assessed according to the factors enumerated in Table 2. Pulsus paradoxus was noted in only 3 patients and is often not appreciated as a sign of the severity of asthma. The infrequency of ECG records on admission probably reflects the lack of awareness of the acute changes that can occur with status asthmaticus.

Thirteen patients were in hospital for at least $24 \mathrm{hr}$ before ventilation. Six patients were on intravenous hydrocortisone in a range of $200-400 \mathrm{mg}$ 3-hourly. Two patients were on oral steroids $(60$ and $80 \mathrm{mg}$ daily). Eight patients were on intravenous aminophylline in addition to intravenous steroids. In patient no. 11 the severity of the situation was not appreciated and she was sent to the day ward, for observation, on no treatment, even though it was recorded in the notes that she was too breathless to give a history.

\section{Factors leading to the necessity for ventilation}

The 20 patients came to ventilation for one of 3 reasons - (1) sedation producing respiratory depression and carbon dioxide narcosis, (2) sudden unexpected respiratory arrest, (3) elective ventilation due to exhaustion and/or carbon dioxide narcosis.

(1) Seven patients received sedatives whilst in status asthmaticus (see Table 4). A rise in $P \mathrm{~A}, \mathrm{CO}_{2}$ followed by clinical deterioration was noted in 6 of these patients. Blood gases were all taken after administration of the sedative and just before ventilation, except for patient no. 5 in whom they were taken at the time of respiratory arrest. Patient no. 8 was on maintenance diazepam; the drug was probably only a minor factor in the deterioration of her asthma.

(2) Six patients were ventilated urgently following either a respiratory arrest or intractable bronchospasm. Two of these 6 patients arrested suddenly in Casualty, and one whilst being transferred to hospital. One patient (no. 5) had a sudden unexpected respiratory arrest on the ward at 10 p.m. having received $60 \mathrm{mg}$ of prednisolone during the afternoon of the same day. At this time he was fully mobile and gave a fluent history, although his peak flow was only 80 litres/min (Table 4). Patient no. 17 , a nurse on duty, unwittingly ingested a nutcontaining chocolate (being highly allergic to nuts) and developed acute bronchospasm with a respiratory arrest. The sixth patient developed intractable bronchospasm and required ventilation for 6 days following administration of thiopentone.

(3) Eight patients were electively ventilated following failure of conventional treatment of intravenous/ oral steroids and a bronchodilator. These patients were either extremely exhausted or unable to expectorate. Five patients developed levels of arterial $\mathrm{PCO}_{2}$ above $6.6 \mathrm{kPa}$ before ventilation.

One patient appears both in Group 1 and Group 2. He initially had a respiratory arrest and during resuscitation was given intravenous diazepam. Following extubation he had a further, terminal arrest.

\section{Ventilation and outcome}

Initial hours of ventilation. Intubation was uneventful apart from one patient who developed

TABLE 4. $P_{C_{2}}$ and sedatives received in 7 patients

\begin{tabular}{|c|c|c|c|}
\hline Patient & Drug and route & $\mathrm{PCO}_{2}$ & $\begin{array}{l}\text { Elapse of time } \\
\text { from drug } \\
\text { administration } \\
\text { to ventilation } \\
\text { (hr) }\end{array}$ \\
\hline 1 & Paraldehyde i.m. & $9 \cdot 3$ & 5 \\
\hline $5^{*}$ & Diazepam $10 \mathrm{mg}$ i.v. & $8 \cdot 2$ & $3 \cdot 5$ \\
\hline 7 & $\left.\begin{array}{ll}\text { Promethazine hydrochloride } 25 \mathrm{mg} \\
\text { Nitrazepam } & 10 \mathrm{mg}\end{array}\right\}$ per os & $8 \cdot 6$ & 4 \\
\hline 8 & Diazepam $10 \mathrm{mg}$ per os & $6 \cdot 8$ & 24 \\
\hline 9 & $\begin{array}{l}\text { Chlorpromazine } 25 \mathrm{mg} \\
\text { Pethidine } 50 \mathrm{mg} \text { i.m. }\end{array}$ & $9 \cdot 3$ & 2 \\
\hline 10 & Diazepam $5 \mathrm{mg}$ i.v. & $13 \cdot 7$ & 2 \\
\hline 11 & Diazepam $5 \mathrm{mg}$ per os & not done & 3 \\
\hline
\end{tabular}

* This patient had a respiratory arrest and was given i.v. diazepam at time of arrest. Resuscitation was successful but he was extubated immediately and had a further respiratory and cardiac arrest $3 \cdot 5$ hr later. 
laryngeal spasm. During the first few hours of ventilation airway pressures were extremely high and ventilation had to be adjusted so that adequate cardiac and urine output was maintained. Ideal blood gas figures were rarely obtained within the first $24 \mathrm{hr}$ of ventilation.

Pneumothorax. Two patients developed pneumothoraces whilst being ventilated. In both patients airway pressures were extremely high, being maintained initially between 50 and $80 \mathrm{~cm} \mathrm{H}_{2} \mathrm{O}$. Both these patients eventually succumbed whilst being ventilated although not at the time of occurrence of their pneumothoraces.

Tracheostomies. Six patients who were ventilated for more than 7 days had tracheostomies. In 5 patients adequate spontaneous ventilation was not achieved with an endotracheal tube in position bronchospasm increasing as sedation was decreased. One patient was extubated and failed spontaneously to breathe adequately - it was felt therefore that a planned tracheostomy following re-intubation was indicated.

Extubation. Fourteen patients wère extubated once the asthma had resolved, and 6 patients had considerable difficulty in weaning from the ventilator. Often, with reduction in the level of sedation or following extubation, there was reactive bronchospasm.
Dysrhythmias. Two patients developed supraventricular tachycardia. One of these developed ECG changes compatible with a subendocardial infarct.

\section{Complications of ventilation in the patients who survived}

Time spent on the ventilator ranged from 1 to 14 days, the mean time being 3 days. Two patients (no. 3 and no. 20) had to be ventilated for a period longer than anticipated because of lung infections. Patient no. 20 developed staphylococcal lung abscesses.

Mortality during artificial ventilation. Seven patients died whilst being ventilated. The average age of those patients who survived was 40 years and that of the non-survivors 49 years. Details are shown in Table 5 . In 4 patients there were possible avoidable factors; 3 patients had respiratory arrests before ventilation and would undoubtedly have died at that time had resuscitation facilities not been available. All these patients had exceptionally high ventilatory pressures which probably predisposed 2 of them to developing pneumothoraces. Thick secretions were also a prominent feature of these patients.

Cardiac failure related to the onset of a dysrhythmia or prolonged right heart strain was an important factor contributing to deterioration during

TABLE 5. Manner of death in 7 asthmatics

\begin{tabular}{|c|c|c|c|c|}
\hline Patient & $\begin{array}{c}\text { Age } \\
\text { (years) }\end{array}$ & Sex & Factors contributing to death & Possible avoidable factors \\
\hline 5 & 35 & $\mathbf{M}$ & $\begin{array}{l}\text { Sudden respiratory arrest at } 10 \text { p.m. } \\
\text { Peak flow } 6 \text { hr before } 80 \text { litres } / \mathrm{min} \text {. } \\
\text { Diazepam given i.v. during arrest and extubated } \\
\text { after successful resuscitation }\end{array}$ & Diazepam $10 \mathrm{mg}$ i.v. \\
\hline 7 & 68 & $\mathrm{~F}$ & $\begin{array}{l}\text { Sedatives administered, promethiazine hydrochloride } \\
\text { and nitrazepam } \\
\mathrm{PCO}_{2} 8 \cdot 6 \text {. Infection. Old age. } \\
\text { Steadily deteriorated on ventilator }\end{array}$ & $\begin{array}{l}\text { Promethazine hydrochloride and } \\
\text { nitrazepam }\end{array}$ \\
\hline 12 & 58 & $\mathbf{F}$ & $\begin{array}{l}\text { Transfer from another hospital. } \\
\text { No oxygen for } 3 \text { min in ambulance and respiratory } \\
\text { arrest in casualty dept. } \\
\text { Steady deterioration on ventilator }\end{array}$ & $\begin{array}{l}\text { Lack of oxygen when in status } \\
\text { asthmaticus contributing to } \\
\text { respiratory arrest }\end{array}$ \\
\hline 14 & 54 & $\mathbf{F}$ & $\begin{array}{l}\text { Intractable bronchospasm. Full treatment and } \\
\text { electively ventilated. High airways pressures. } \\
\text { Pneumothorax and renal failure }\end{array}$ & None \\
\hline 15 & 62 & $\mathrm{~F}$ & $\begin{array}{l}\text { Thick secretions. Narcosed. Steady deterioration on } \\
\text { ventilator }\end{array}$ & None \\
\hline 17 & 48 & $\mathbf{F}$ & $\begin{array}{l}\text { Respiratory arrest in casualty dept. Thick sputum. } \\
\text { High airway pressures. Had stopped own ACTH } \\
\text { before attack. Pulmonary emboli whilst on } \\
\text { ventilator? }\end{array}$ & $\begin{array}{l}\text { Stopped her ACTH } 6 \text { weeks } \\
\text { before final attack }\end{array}$ \\
\hline 18 & 19 & $\mathrm{~F}$ & $\begin{array}{l}\text { Labile asthmatic. Pneumothorax on ventilator. } \\
\text { High airway pressures. Eventual heart failure }\end{array}$ & None \\
\hline
\end{tabular}


ventilation. Patient no. 5 was an exception in that he was extubated after resuscitation and was only ventilated for $45 \mathrm{~min}$ after re-intubation before sustaining a cardiac arrest.

Late deaths. Patient no. 2, following successful resuscitation (he was brought into Casualty unconscious following excessive use of his 'medihaler'), was found dead at home 3 months later. The cause of death, following a post-mortem, was attributed to status asthmaticus.

Survivors. Twelve patients are alive at most recent follow-up. Ten of these patients were electively ventilated whilst in hospital, the eleventh patient was ventilated urgently following the administration of thiopentone sodium which produced acute bronchospasm, and the twelfth patient, a nurse, who had a respiratory arrest whilst on duty in the wards, received immediate resuscitation and required ventilation for only $24 \mathrm{hr}$. Five of these 12 patients had received sedatives and were narcosed but, once ventilation had been established electively, their course was uneventful. No pneumothoraces or cardiac irregularities were experienced by these patients, although 4 had tracheostomies. The length of time on the ventilator did not differ from that of those patients who died.

Following discharge from hospital, 7 patients required further hospital admission although none was ventilated. Three of these remained on oral steroids. Of interest, 5 patients were discharged from out-patient follow-up, although 2 later required hospital admission for exacerbation of asthma. Two patients did not keep their out-patient clinic appointments.

\section{Discussion \\ Morbidity and mortality}

Asthma is a common condition with a high morbidity and mortality. During the years 19591966 the annual number of deaths from asthma increased from 123 to 431 and the death rate trebled from 0.7 to 2.2 per 100000 persons (Speizer, Doll and Heaf, 1968a). This increase (Speizer et al., 1968b; Inman and Adelstein, 1969) partially attributed to the overuse of sympathomimetic aerosols has now abated but the anxiety which a patient in status asthmaticus provokes is still justified. Death can occur suddenly and unexpectedly outside hospital before medical help can be obtained (Frazer et al., 1971; MacDonald, Seaton and Williams, 1976). MacDonald et al. described 90 asthma deaths occurring outside hospital between 1963 and 1974 . Of these 90, 20 died before a doctor arrived, 22 were dead or dying on arrival of the doctor and 10 died in the ambulance or whilst waiting for it.

Fortunately, most patients in status asthmaticus requiring admission to hospital receive and respond to conventional therapy of intravenous steroids and bronchodilators. The emphasis on team approach with admission of asthmatics to special observation units (Jones, 1971) has done much to improve their management. Further, the Edinburgh self-admission service (Crompton and Grant, 1975) has not had any asthmatics dying for want of admission to hospital since it was established.

Patients coming to ventilation are rare, but they indicate either failure of proper conventional therapy, therapeutic misadventure, or else unexpected respiratory arrest (which may not necessarily be a consequence of the other 2 factors).

In the present series, carbon dioxide narcosis was undoubtedly induced in those patients who received sedatives whilst in status asthmaticus, deterioration occurring in their level of consciousness within hours. Cochrane and Clarke (1975) who studied 19 patients who died in the hospitals of greater London in 1971, found that 15 of these patients had received sedatives. They stress the failure to appreciate and adequately assess the severity of the illness.

In 4 patients there were possible avoidable causes. Two patients had withdrawn their own steroid medication without consulting their doctors. Responsibility for education of the patient about his illness must lie with the doctor and should be reinforced at each attendance, especially if the patient is steroid-dependent. Inadequate education led one patient to overuse his sympathomimetic aerosol. Patients fail to appreciate that the doctor must be informed if there is any tendency towards asthma; this applies particularly if the patient is due to receive any form of medication. The fourth patient, a nurse, told the anaesthetist that she had been previously well and had experienced no drug allergy. She developed acute bronchospasm with intravenous thiopentone. Many agents used during anaesthesia have a broncho-constrictor action (Aviado, 1975). The remaining patients were ventilated either because of increasing respiratory failure or following an unexpected respiratory arrest.

\section{Pathophysiology}

The physiological derangements in severe asthma can be considered under 3 headings: (1) a marked increase in the work of breathing; (2) varying degrees of shunting; (3) the effects of hyperinflation and increased intrapulmonary pressure on the heart and circulation.

The increase in airways resistance in the asthmatic leads to an increase in the flow-resistive work necessary to obtain adequate ventilation, and the decrease in compliance caused by hyperinflation leads to an increase in the elastic work necessary to maintain adequate ventilation. The resistance to 
expiration is usually greater than the resistance to inspiration and, in severe asthma, the diaphragm and abdominal muscles are used as active expiratory muscles to overcome the increased resistance. The uneven distribution of ventilation caused by uneven airways obstruction, and the expansion of the pulmonary vascular bed, lead to varying degrees of inequality in the ratio of alveolar ventilation to pulmonary perfusion/unit time. with a fall in $P_{\mathrm{A}}, \mathrm{O}_{2}$ and ultimately a rise in $P_{\mathrm{A}}, \mathrm{CO}_{2}$. Right and left ventricular filling is limited by the high intrapulmonary pressure and the pericardial stretching in the hyperinflated chest (akin to tamponade). This leads to an increased right atrial pressure. Cardiac output may be maintained despite a decrease in stroke volume by a compensatory tachycardia. The raised intrapulmonary pressure increases the right ventricular afterload and thereby increases the stroke work. The ECG may show signs of right heart strain. Left ventricular output varies immensely with left ventricular afterload (aortic pressure minus intrapulmonary pressure) and so varies with respiration (pulsus paradoxus). The pathophysiology of death in asthmatics is uncertain but is probably the result of a combination of factors. Increasing hypoxia and acidosis are associated with a progressive increase in pulmonary vascular resistance. If venous return and right ventricular filling are compromised by a high intrapulmonary pressure to the extent that the right ventricle cannot overcome the increased pulmonary vascular resistance, then acute right heart failure occurs. Furthermore, the increased sympathetic activity associated with hypoxia and acidosis may predispose the heart to serious dysrhythmias.

Grunstone (1971) performed right heart catheter studies in 9 patients who had exacerbations of their asthma, 5 of whom had ECG abnormalities and found their right heart pressures to be normal or low. There was no difference in the pressure between those patients with normal and abnormal ECGs. Ambiavagar and Sherwood Jones (1967) described a rise in pulmonary artery pressure in a severely ill ventilated asthmatic.

The present authors investigated only one patient in whom the pulmonary artery pressure was found to be low; the right atrial pressure was raised with a low cardiac output. A threefold improvement in cardiac output (from 3 to 9 litres/min with a fluid challenge of $800 \mathrm{ml}$ of plasma) indicated an inadequate right ventricular filling pressure rather than right heart failure. Pulmonary vascular resistance remained normal. Blood gases remained essentially unchanged, although there was a noticeable improvement in the patient's level of consciousness. The pulmonary vascular bed had therefore dilated in response to the increased right ventricular output and there was improved transport of the available oxygen to the peripheries. At a later stage in the illness, when the $P \mathrm{~A}, \mathrm{CO}_{2}$ was elevated, both the pulmonary artery pressure and the pulmonary vascular resistance were found to be raised.

\section{Ventilation}

Introduction. Ventilation in the most favourable circumstances should be an elective procedure, conducted in consultation between the anaesthetist and a physician experienced in the management of patients with obstructive airways disease.

Pulmonary complications which may lead to sudden respiratory arrest include acute tension pneumothorax or lung collapse. The onset of cardiac failure or a cardiac dysrhythmia are particularly dangerous in the older asthmatic. Severe bronchial asthma is often complicated by dehydration, a low circulating blood volume and hence lactic acidosis. Such complications compound the already difficult task of anaesthetizing an asthmatic for ventilation.

Criteria for ventilation. The aims of ventilation are to relieve the patient of the work of breathing, to restore the blood gases to normal, and to allow removal of some of the retained secretions. Suggested criteria for ventilation are enumerated in Table 6. Exhaustion, with disturbances of consciousness and diminishing respiratory effort are absolute indications for ventilation. In a patient whose clinical condition is deteriorating despite a reasonable period of appropriate therapy, the decision to ventilate should be made before the patient is moribund.

The inability of an asthmatic to co-operate in lung function studies is often in itself indicative of an extremely severe attack.

Sequential assessment of the acid base state and blood gases is essential (Table 6); a rising $\mathrm{PA}_{\mathrm{A}}, \mathrm{CO}_{2}$ is generally evidence of exhaustion and is often accompanied by an increasing metabolic acidosis.

Pulsus paradoxus (Rebuck and Pengelly, 1973) of more than $10 \mathrm{mmHg}$ and ECG evidence of right heart strain or dysrhythmia (Siegler, 1977), are all indicators of the effect of high inflation pressures on the heart. Chest X-ray is essential and should be taken if possible just before ventilation. A pneumothorax must be drained before ventilation is instigated. Acute pneumomediastinum may produce a fall in cardiac output and a severe decrease in lung compliance. Emergency intubation and hand ventilation may therefore be indicated; in such cases it is important to be aware that pneumomediastinum is generally followed by the development of a pneumothorax which must be drained as soon as it is detected.

Ventilatory procedure. The manner in which these acutely ill patients are anaesthetized is of vital importance. Careful preparation of the patient, with a smooth induction and intubation are mandatory. 
TABLE 6. Suggested criteria for ventilation based on sequential observations

1. Evidence of deterioration in pulmonary function

Steady fall in $\mathrm{PA}_{\mathrm{A}} \mathrm{O}_{2}$ and a rising $\mathrm{PA}_{\mathrm{A}}, \mathrm{CO}_{2}$.

Danger levels in a primary asthmatic are probably a $P \mathrm{~A}, \mathrm{O}_{2}$ of $40 \mathrm{mmHg}$ or less $(5.3 \mathrm{kPa})$ and a $P_{\mathrm{A}}, \mathrm{CO}_{2}$ of $50 \mathrm{mmHg}$ or more $(6 \cdot 7 \mathrm{kPa})$.

Respiratory function studies (peak flow, forced vital capacity) can rarely be obtained in these patients.

2. Evidence of deterioration in cardiac function

Rising pulse rate $(>140 / \mathrm{min}$ for $>3 \mathrm{hr}$ ), fall in pulse volume, presence of pulsus paradoxus $(>10 \mathrm{mmHg})$.

Onset of a cardiac dysrhythmia.

Rising right atrial pressure.

3. General evidence of deterioration

Deterioration level of consciousness.

Fall in urine output.

Onset of a metabolic acidosis.

Emergency indications for ventilation in a severe asthmatic may include:

1. Irreversible respiratory depression due to drugs.

2. Lung collapse, acute pneumothorax or pneumomediastinum.

3. Onset of a cardiac dysrhythmia or evidence of heart failure.

(Each patient has to be assessed individually. It is therefore difficult to place absolute values for ventilation.)

Before ventilation - except in an extreme emergency - an adequate circulating blood volume must be achieved. The right atrial pressure is generally raised in an asthmatic and may give a false impression of the adequacy of right ventricular filling. Therefore, the right ventricle should be loaded by a series of fluid challenges - aliquots of an appropriate fluid, e.g. purified protein fraction is given in a volume of $200 \mathrm{ml}$ at 10 -min intervals, the right atrial pressure (RAP) being measured $5 \mathrm{~min}$ after each aliquot. Should the RAP remain the same, fluid challenges can be continued until the RAP rises and stays above the original level. Should the RAP be very high before intubation $\left(>18 \mathrm{~cm} \mathrm{H}_{2} \mathrm{O}\right)$ and the pulse volume poor, right ventricular failure may be present. Under such relatively rare circumstances, insertion of a thermodilution catheter and measurement of right ventricular output should be considered (see para. 4 under 'Monitoring'). The asthmatic in such a situation is generally so desperately hypoxic that intubation and hand ventilation are indicated relying on right atrial pressure monitoring, a thermodilution catheter being inserted as soon as time allows.

Electrolyte imbalance is common, the commonest being that of hypokalaemia (probably accentuated by steroid therapy and the renal tubular response to stress) and hyponatraemia. The hyponatraemia rarely signifies a depletion of total body sodium, and sodium ions are not indicated unless there has been overt loss (e.g. vomiting). A serum potassium of less than $3.3 \mathrm{mmol} / \mathrm{l}$ is an absolute indication for potassium infusion, keeping in mind that a serum potassium at the lower limit of normality in the presence of a metabolic or respiratory acidosis, signifies a greater depletion of total body potassium than when associated with an alkalosis.

A respiratory and metabolic acidosis is common sodium bisarbonate is rarely indicated, but should the pH be 7.2 or less and the component bs largely metabolic, $50 \mathrm{mmol}$ of bicarbonate should be considered. Sodium bicarbonate should not be given if the serum potassium is $3.2 \mathrm{mmol}$ or less.

A naso-gastric tube is passed and the gastric contents aspirated. These patients may sometimes have an ileus. The $\mathrm{pH}$ of the aspirate is tested and antacids administered routinely.

\section{Anaesthetic technique}

The choice of an induction agent is limited in asthmatics. Many induction agents cause a fall in cardiac output and some drugs used in anaesthesia may liberate histamine which may further aggravate bronchospasm (Aviado, 1975). A gaseous induction may therefore be preferred, bearing in mind that the patient may vomit, so full emergency precautions should be employed. Often the patient cannot lie down and must be anaesthetized in a semi-recumbent position. In the Whipps Cross Hospital unit the preferred technique is a halothane, nitrous oxide, oxygen induction until the patient has settled, followed by i.v. pancuronium, gradually taking over ventilation by hand. When fully relaxed, the vocal cords are sprayed with $4 \mathrm{ml}$ of $4 \%$ lignocaine and an oral cuffed portex endotracheal tube inserted. This technique avoids the potential hazards of suxamethonium, although suxamethonium may be indicated when a rapid induction is required. The 
authors have found a combination of diazepam and phenoperidine a useful intravenous induction in asthmatics.

Ventilatory technique. Once the patient has settled on hand ventilation, mechanical ventilation with humidification is initiated. The problems encountered in ventilating an asthmatic are manifold. The ventilator chosen must be capable of delivering an adequate volume against a high resistance into a comparatively non-compliant thorax. A variable $I: E^{*}$ ratio is a great advantage and an expiratory resistance may be of some use. A pause time allows more useful distribution of the inspired gases to the more obstructed portions of lung.

Ventilation must be optimized by auscultation of the chest. The expiratory time should be sufficiently long to allow all expiratory rhonchi to cease. If the inspiratory phase begins before this, further air trapping may occur. Careful use of a minimal expiratory resistance may theoretically improve lung emptying by preventing small airway closure. It has yet to be shown to be of value in this condition, its use having many inherent dangers, including increasing the inflation pressure and further distorting the relationship between ventilation and perfusion.

For a given inspiratory resistance, the airway pressure is a function of the inspiratory flow and the inspiratory time. The flow should be sufficiently low and the time sufficiently long to prevent airway pressures from reaching dangerously high levels. A high endotracheal cuff inflation pressure is required at high airway pressures, and tracheal damage may result.

A balance must be achieved between ventilatory settings which achieve a stable cardiovascular system and which allow optimum gas exchange. The authors used low min volumes (6-10 litres) with slow respiratory rates $(10-14 / \mathrm{min})$. The ventilators used were Engström $300 \dagger$, a volume pre-set time-cycled pressure generator with a fixed I : E ratio, or a Servo 900‡, a time-cycled flow generator with variable $I: E$ ratio. Both offer an expiratory resistance. The Servo 900 was preferred because of the control it allows over the respiratory cycle and waveform.

Monitoring. Monitoring the blood gases usually shows an immediate improvement in $P_{A}, O_{2}$ and a gradual fall in $P_{\mathrm{A}}, \mathrm{CO}_{2}$. As the cardiac output may be partly sustained by hypercarbia and hypoxia (both directly and indirectly through circulating catecholamines), care must be taken not to reduce the $P \mathrm{~A}, \mathrm{CO}_{2}$ by more than $10 \mathrm{mmHg}(1.3 \mathrm{kPa})$ per hr. The fractional concentration of oxygen in inspired

\footnotetext{
* Ratio of inspiratory time to expiratory time during artificial ventilation.

$\dagger$ (L. K. B. Medical.) $\ddagger$ (Siemens Elema.)
}

gas is adjusted to maintain the $P \mathrm{~A}, \mathrm{O}_{2}$ within normal limits.

The airway pressure is recorded and the chest circumference is measured at regular intervals; too rapid deflation may cause a relative decrease in airway bore (an increase in bronchoconstriction) with further air trapping.

The ECG is monitored for arrhythmias and for signs of right heart strain and daily ECGs recorded.

In situations where the right atrial pressure is high and the pulse volume low with an associated poor urine output, insertion of a thermodilution catheter for monitoring of right ventricular cardiac output and pulmonary capillary wedge pressure (PCWP) is to be recommended. By this method, cardiac output can be optimized by adjustment of the intravascular volume and ventilatory indices. PCWP measurements give a guide to left atrial pressure and should be maintained below $17 \mathrm{mmHg}$ (in the presence of a normal serum albumin) in order to prevent left ventricular overload.

Daily chest X-rays will show a reduction in the degree of overinflation, and may show the development of pneumothorax, pneumomediastinum or infection. Anaerobic and aerobic cultures of the sputum should be taken daily.

\section{Drug therapy}

Sedation and relaxation. Phenoperidine $2 \mathrm{mg}$ and diazepam $10 \mathrm{mg}$ are used for sedation and repeate as often as necessary. Pancuronium $4 \mathrm{mg}$ is given hourly for relaxation. These drugs are free from histamine release and have negligible effects on the cardiovascular system once the system has become adjusted to ventilation.

Steroids and bronchodilators. Hydrocortisone should be given as $200 \mathrm{mg}$ i.v. every $2 \mathrm{hr}$ (doubled if the patient was receiving steroids before admission) until an improvement is seen. A dose of up to $4 \mathrm{~g}$ in $24 \mathrm{hr}$ may be used (Rebuck and Pengelly, 1973). In asthmatics who are elderly, prednisolone should be used in order to decrease the likelihood of fluid retention or urinary potassium loss.

In the hypoxic asthmatic $\left(\mathrm{PA}_{\mathrm{A}} \mathrm{O}_{2} 60 \mathrm{~mm}(8.0 \mathrm{kPa})\right.$ or less) or where the pulse rate is $>120 / \mathrm{min}$, bronchodilators are not used intravenously since they may increase the ventilation perfusion deficit (Palmer, 1971). Once the ${\mathrm{PA}, \mathrm{O}_{2}}_{2}$ has improved, bronchodilators are titrated intravenously with caution, the effect being optimized according to the changes in pulse rate, airway pressure and $P_{\mathrm{A}}, \mathrm{O}_{2}$. Salbutamol may be administered via a suitable nebulizer (e.g. the Bird nebulizer) at a dose of 2-5 mg 2-hourly, preceding physiotherapy. Lignocaine $4 \%$ topical solution $(40 \mathrm{mg})$ may be added to this to reduce bronchospasm during physiotherapy and suction. 
On rare occasions when the cardiac output is low in the presence of evidence of impaired perfusion (oliguria, cold extremities), an inotropic agent such as isoprenaline, titrated intravenously in minute dosage should be considered, when all other attempts at improving cardiac output (fluid top-up, variation of ventilatory indices) have failed.

High airway pressure and severe bronchospasm may persist for at least $24 \mathrm{hr}$ before there is evidence of improvement. Maintenance of an adequate circulating blood volume, treatment of any cardiac dysrhythmia or metabolic imbalance and early detection and appropriate management of any complication is imperative at this stage. Total relaxation and heavy sedation of the patient is essential, and hand ventilation and suction should only be performed when there is evidence of sputum retention.

Steroids must not be tapered-off too rapidly, since this frequently causes a recurrence of spasm. Once the airway pressures are consistently falling, the dosage should be reduced on alternate days to reach a dosage of prednisolone $10 \mathrm{mg}$ thrice daily (or its equivalent) over a period of approximately 10 days.

Resistant bronchospasm. Anaesthesia with diethyl ether was used on 2 patients with resistant bronchospasm. Ether is useful as it is a powerful bronchodilator and causes bronchorrhoea, thereby thinning and loosening inspissated secretions. There have been recent reports of the successful use of ketamine hydrochloride to terminate bronchospasm in status asthmaticus resistant to other forms of treatment (Betts and Parkin, 1971). It must be remembered, however, that ketamine has also been shown to release histamine in some patients (Mathieu, Goodsouzian and Snider, 1975).

Removal of secretions. Restricted lavage only was used (10-20 ml of warm isotonic saline injected down the endotracheal tube). This enabled more sputum to be aspirated from patients with thick secretions. Bromhexine was used to liquefy secretions both intramuscularly and via the humidifier $(4 \mathrm{mg} / \mathrm{l})$. Bromhexine should be stopped after 2 or 3 days because of continuing bronchorrhoea. It should be emphasized that effective removal of secretions in patients on ventilators cannot be achieved without the help of skilled physiotherapists.

Other drugs. Digoxin was sometimes given intravenously for the treatment of atrial flutter or fibrillation, or of heart failure. Other antidysrhythmic drugs were rarely used except for the occasional use of intravenous lignocaine for multiple ventricular extrasystoles.

Antibiotics were not used initially except where bronchopneumonia was present on X-ray. Anaerobic and aerobic cultures were taken at the time of intubation and the relevant antibiotic used when a dominant organism considered pathogenic for that patient was isolated. Pseudomonas sp. was frequently detected but rarely treated.

Weaning. When substantial improvement in the bronchospasm had occurred, sedation was stopped and the patient allowed to trigger the ventilator. Difficulties are often encountered at this stage with reactive bronchospasm caused by irritation of the trachea by the endotracheal tube. The process of extubation could precipitate a further attack of bronchospasm in a patient who had seemingly recovered. A suitable way to extubate a patient in whom this appeared likely to be a problem was to anaesthetize him with halothane until laryngeal reflexes were lost, extubate and then support a clear airway until consciousness was regained.

\section{Complications}

Pneumothorax is a constant worry in patients being ventilated with high airway pressures; if not detected immediately, a mediastinal shift with tension may occur with ensuing circulatory arrest.

Atelectasis occurs commonly because of the retained secretions but is usually quick to clear with good physiotherapy. Bronchoscopy is rarely indicated. Consolidation when detected should be treated with appropriate antibiotics.

Tracheostomy is generally delayed until the patient has been ventilated for 7 days. Tracheostomy was found to be particularly valuable in patient weaning where bronchospasm developed when there was a reduction in the level of sedation, in the patient with complications (e.g. bronchopneumonia or atelectasis) and in the patient over 50 years of age.

Acute right heart failure ultimately develops in ventilated patients who maintain high airway pressures for a long time. Two patients in the present series had bronchospasm which was unrelieved at any stage; they developed heart failure, circulatory collapse accompanied by renal failure, and succumbed.

\section{References}

Ambiavagar, M. \& Sherwood Jones, E. (1967) Resuscitation of the moribund asthmatic. Anaesthesia. London, 22 , 375.

Ambiavagar, M., Sherwood Jones, E. \& Roberts, D.V. (1967) Intermittent positive pressure ventilation in severe asthma. Anaesthesia. London, 22, 134.

Aviado, D.M. (1975) Regulation of bronchomotor tone during anesthesia. Anesthesiology. Lancaster, $\mathrm{Pa}$, etc., 42, 68.

BetTS, E.K. \& PARKIN, C.E. (1971) Use of ketamine in an asthmatic child. A case report. Anesthesia and Analgesia Current Researches, 50, 420.

Cochrane, G.M. \& Clark, T.J.H. (1975) A survey of asthma mortality in patients between ages 35 and 64 in the greater London hospitals in 1971. Thorax, 30, 300. 
Crompton, G.K. \& Grant, I.W.B. (1975) Edinburgh Emergency Admission Service. British Medical Journal, 4, 680.

EDITORIAL (1975) Management of acute asthma. British Medical Journal, 4, 65.

Frazer, P.M., SPeizer, F.E., Walters, S.D.M., Doll, R. \& MANN, N.M. (1971) The circumstances preceding death from asthma in young people in 1968 to 1969 . British Journal of Diseases of the Chest, 65, 71 .

GRUNSTONE, R.F. (1971) Right heart pressures in bronchial asthma. Thorax, 26, 39.

InMAN, W.H.W. \& Adelstein, A.M. (1969) Rise and fall of asthma mortality in England and Wales in relation to the use of pressurised aerosols. Lancet, ii, 279.

JONES, E.S. (1971) The intensive therapy of asthma. Proceedings of the Royal Society of Medicine, 64, 1151.

MacDonald, J.B., Seaton, A. \& Williams, D.A. (1976) Asthma deaths in Cardiff 1963-74. 90 deaths outside hospital. British Medical Journal, 1, 1493.
Mathieu, A., Goodsouzian, W. \& Snider, M.T. (1975) Reaction to ketamine: anaphylactoid or anaphylactic. British Journal of Anaesthesia, 47, 624.

PALMER, K.N. (1971) Effect of bronchodilator drugs on arterial blood gas tensions in bronchial asthma. Postgraduate Medical Journal, 47, (Suppl. March), 75.

Rebuck, A.S. \& Pengelly, D. (1973) Development of pulsus paradoxus in the presence of airways obstruction. New England Journal of Medicine, 288, 66.

SiEgler, D. (1977) Reversible electrocardiographic changes in severe asthma. Thorax, 32, 328.

Speizer, F.E., Doll, R. \& Heaf, P. (1968a) Observations on recent increase in mortality from asthma. British Medical Journal, 1, 335.

Speizer, F.E., Doll, R., Heaf, P. \& Strang, L.B. (1968b) Investigations into the use of drugs preceding death from asthma. British Medica! Journal, 1, 339.

STARK, J.E. (1972) Status asthmaticus. British Journal of Hospital Medicine, 8, 241. 